\title{
İzole menisküs tamiri sonrası rehabilitasyon
}

\section{Rehabilitation after the repair of isolated meniscus tears}

\author{
Defne Kaya ${ }^{1}$, Mahmut Çalık , Filiz Eyüboğlu ${ }^{1}$, Hakan Çiçek ${ }^{2}$ \\ `Üsküdar Üniversitesi Sağlık Bilimleri Fakültesi, Fizyoterapi Rehabilitasyon Bölümü; \\ NP Fizyoterapi Rehabilitasyon Merkezi, İstanbul, Türkiye \\ ${ }^{2}$ Sağlık Bilimleri Üniversitesi, Adana Şehir Hastanesi Ortopedi ve Travmatoloji Kliniği, Adana, Türkiye
}

\begin{abstract}
Özellikle genç ve orta yaş popülasyonda, travmatik menisküs yırtıkları sıkça karşımıza çıkan diz içi problemlerden biridir. Yakın tarihte bu yırtıkların onarımının klinik sonuçlar ve eklem kıkırdak sağkalımı için önemi anlaşılmıştır. İzole menisküs yırtıklarında uygulanan farklı cerrahi tekniklerin tamamında cerrahi sonrası rehabilitasyon, tedavinin ayrılmaz bir parçası olarak pratiğimizde yerini almıştır. Hasta gruplarına bağlı olarak uygulanacak kesin rehabilitasyon protokolleri hala tanımlanmamıştır. Bazı yazarlar, hareket ve yük aktarımının kısıtlandığı daha gelenekçi protokoller önerirken, diğerleri hızlandırılmış protokoller önermektedir. Son dönemlerdeki yayınlarda hızlandırılmış protokoller sıkça tartışılmaktadır. Bu çalışmalarda, hızlandırılmış rehabilitasyon programları ile yeterli klinik sonuçlar bildirilmiştir. Bu derlemede, izole menisküs yırtıklarının onarımı sonrası rehabilitasyon programları ana başlıklar halinde ele alınmıştır. Farklı rehabilitasyon protokollerinin klinik sonuçları, tedavi yetmezlikleri üzerindeki etkileri, karşılaştırmalı çalışmalarla değerlendirilmiştir.
\end{abstract}

Anahtar sözcükler: menisküs; yırtık; onarım; cerrahi; rehabilitasyon
Traumatic meniscal tears, especially in young and middleaged populations, are one of the most common intra-articular problems. In recent years, the repair of these tears has been understood to have clinical implications for the survival of joint cartilage. All the different surgical techniques applied to isolated meniscal tears are an integral part of postoperative rehabilitation therapy. Definitive rehabilitation protocols which should be applied to the patient groups are still undescribed. While some authors are suggesting more conventional protocols restricted by movement and load transfer, others suggest accelerated protocols. In the recent literature, accelerated protocols are frequently discussed. These studies have also reported satisfactory clinical outcomes about accelerated rehabilitation programs. In this review, rehabilitation programs after the repair of isolated meniscus tears are covered as main topics. The clinical outcomes of different rehabilitation protocols and the effects on treatment failures were evaluated by comparative studies.

Key words: meniscus; tear; repair; surgery; rehabilitation
M enisküs yırtıklarının cerrahi tedavisinde menisküs tamirinin büyük bir önem kazanması ile, cerrahi sonrası rehabilitasyon stratejileri de cerrahi başarıyı arttıran bir süreç olarak değer kazanmaktadır. Günümüzde, menisküs tamirleri sonrası için fikir birliğine varılmış ve standart hale getirilmiş fizyoterapi rehabilitasyon protokolleri ne yazık ki bulunmamaktadır. Literatür incelendiğinde, ağırlık aktarma, normal eklem hareket sınırı ve tedavi ilerleme ölçütleri ile spora dönüş ölçütleri çok değişim göstermektedir.

Cerrahi sonrası ne kadar ve ne zaman ağırlık verileceği, eklem hareketinin hangi sınırlarda ve hangi zaman aralıklarında yapılacağı; tamir bölgesine binen yüklerin oranı ve iyileşme sürecine etkileri nedeniyle aslında çok önemli konulardır. Vertikal ve longitudinal yırtıkların kompresif kuvvetlerle, radyal yırtıkların distraksiyon ve aksiyel kuvvetlerle arttığı düşünüldüğünde, cerrahi sonrası erken dönemde ağırlık aktarmalara karar vermenin kritik önemi anlaşılacaktır. Cerrahi sonrası rehabilitasyon adımlarına, cerrahi teknik, yırtığın tipi ve hastanın aktivite seviyesine göre karar verilmelidir.

Bu bölümün amacı, izole menisküs yırtıklarının tamirleri sonrası rehabilitasyon stratejilerini bir araya getirmektir.

- Illetişim adresi: Doç. Dr. Defne Kaya, Üsküdar Üniversitesi, Sağlık Bilimleri Fakültesi, Fizyoterapi Rehabilitas-yon Bölümü, Mahir İz Caddesi, No: 23, 34674 Altunizade, Üsküdar, İstanbul, Türkiye Tel: 0216 - 4181500 e-posta: defne.kaya@uskudar.edu.tr

- Geliș tarihi: 1 Mart 2018 Kabul tarihi: 1 Mart 2018 


\section{IZOLE MENISKÜS TAMIRI SONRASI REHABILITASYON PROTOKOLLERI}

Literatürde menisküs tamirleri sonrası rehabilitasyon süreçleri dört tip protokolle izlenmektedir:

1) Hızlandırılmış rehabilitasyon protokolü. $.1,2]$

2) Hareket kısıtlanmış rehabilitasyon protokolü.[3,4]

3) Ağırlık aktarma kısıtlanmış rehabilitasyon protokolü. ${ }^{[5-8]}$

4) Hareket ve ağırlık aktarma kısıtlanmış rehabilitasyon protokolü. ${ }^{[1,2,9-15]}$

Dört farklı rehabilitasyon protokolü ve bunların süreçleri incelenecek olursa:

\section{Hızlandırılmış Rehabilitasyon Protokolü}

Lind ve ark. ${ }^{[1]}$, stabil olmayan vertikal yırtıkların hepsi içeride dikiş tekniği ile onarılması sonrası uyguladıkları hızlandırılmış rehabilitasyon protokolü ile $\% 72$ başarı, Suganuma ve ark. ${ }^{[2]}$ ise içeriden dışarıya dikiş tekniği ile tamir edilen kova sapı yırtıklarda hızlandırıımış rehabilitasyon protokolü sonrası \%100 başarı elde etmişlerdir. Rehabilitasyon süreçleri Tablo 1'de gösterilmiştir. Lind ve ark.[1], iki ylllık ortalama takip sonucunda, Tegner skorunun rehabilitasyon ile $4,1 \pm 2,2^{\prime}$ den $4,5 \pm 1,9^{\prime}$ a, Suganuma ve ark. ${ }^{[2]}$ ise 3,8 ylllik ortalama takip sonucunda, Lysholm skorunun 97,1 $\pm 3,5$ 'a ve Tegner skorunun da 4,9'dan 4,7'e geldiğini belirtmişlerdir.

\section{Hareket Kısıtlanmış Rehabilitasyon Protokolü}

Stein ve ark. ${ }^{[3]} 2010$ yllında, Eggli ve ark. ${ }^{[4]}$ da 1995 yııında yaptıkları çalışmalarında, içeriden dışarıya dikiş̧ tekniği ile tamir edilen stabil olmayan vertikal yırtıkların, hareket kısıtlama stratejisi ile takip edilen rehabilitasyon süreçlerinin başarı oranlarını sırasıyla $\% 100$ ve $\% 73$ olarak göstermişlerdir. Rehabilitasyon süreçleri Tablo 2'de gösterilmiştir. Stein ve ark. ${ }^{[3]}, 2,49$ ylllık ortalama takip sonucunda, Tegner skorunun rehabilitasyon ile yaralanma öncesine oranla $6,3 \pm 0,6$ 'dan $5,9 \pm 0,7$ 'e ve Lysholm skorunun da $96,5 \pm 7,2$ 'e geldiğini belirtirlerken, Eggli ve ark. ${ }^{[4]}$ ise 7,5 yillık ortalama takip sonucunda, herhangi bir sonuç belirtmemişlerdir.

\section{Ağırlık Aktarma Kısıtlanmış Rehabilitasyon Protokolü}

Choi ve ark. ${ }^{[5]}$, lateral menisküsün radyal yırtığına yönelik hepsi içeride dikiş tekniği kullandıkları çalışmalarında, Englund ve ark. ${ }^{[6]}$, kova sapı ve vertikal yırtıkların onarımında hepsi içeride dikiş tekniği kullandıkları çalışmalarında, Krych ve ark.[7], vertikal, kova sapı ve kompleks yırtığı olan pediatrik hastalarının

Tablo 1. Hızlandırılmış rehabilitasyon protokolü

\begin{tabular}{|c|c|c|c|c|c|}
\hline Çalışma & $\mathrm{NEH}$ & Ağırlık aktarma & Koşma & Spora dönüş & Rehabilitasyon detayı \\
\hline Lind ve ark. ${ }^{[1]}$ & $\begin{array}{l}\text { 1-2 hafta: } 0-90^{\circ} \\
\text { 3-6 hafta: Tam NEH }\end{array}$ & $\begin{array}{l}\text { 1-2 hafta: PUBAA } \\
\text { 3-6 hafta: TEKAA }\end{array}$ & 8. hafta & 12. hafta & Dizlik yok \\
\hline Suganuma ve ark..$^{[2]}$ & $\begin{array}{l}\text { 1. gün başlanılır, tolere } \\
\text { ettikçe arttırma }\end{array}$ & $\begin{array}{l}\text { 1. hafta: HAA } \\
\text { 2. hafta: KAA } \\
\text { 3. hafta: TAA }\end{array}$ & $x$ & 12. hafta & $\begin{array}{l}\text { Topuk üzerine oturma: } \\
\text { 4. hafta }\end{array}$ \\
\hline
\end{tabular}

NEH, normal eklem hareketi; PUBAA, parmak ucuna basarak ağılık aktarma; TEKAA, tolere edebildiği kadar ağılık aktarma; HAA, hiç ağırlık aktarmama; KAA, kısmi ağırlık aktarma; TAA, tam ağılık aktarma; $X$, uygulanmamış/belirtilmemiş.

Tablo 2. Hareket kısıtlanmış rehabilitasyon protokolü

\begin{tabular}{|c|c|c|c|c|c|}
\hline Çalışma & $\mathrm{NEH}$ & Ağırlık aktarma & Koşma & Spora dönüş & Rehabilitasyon detayı \\
\hline Stein ve ark. ${ }^{[3]}$ & $\begin{array}{l}0-4 \text { hafta: } 0-60^{\circ} \\
>6 \text {. hafta: Tam NEH }\end{array}$ & $\begin{array}{l}\text { 0-4 hafta: KD ile TAA } \\
>6 \text { hafta: Tam NEH }\end{array}$ & $x$ & $x$ & $\begin{array}{l}\text { 0-4 hafta: Dizlik } \\
\text { 1. günden itibaren: Pasif } \\
\text { tam NEH ve izometrik KKZE }\end{array}$ \\
\hline Eggli ve ark. ${ }^{[4]}$ & 0-6 hafta: Hareketsiz & TAA & $x$ & 12. hafta & $\begin{array}{l}0-6 \text { hafta: Posterior splint } \\
\text { ile hareketsiz } \\
0-16 \text { hafta: Spora ya da } \\
\text { stres yüklenen hareketler } \\
\text { yasak }\end{array}$ \\
\hline
\end{tabular}

NEH, normal eklem hareketi; TAA, tam ağılık aktarma; KD, koltuk değneği; KKZE, kapalı kinetik zincir egzersizleri; X, uygulanmamış/belirtilmemiş. 
cerrahilerinde içeriden dışarıya ve hepsi içeride dikiş tekniği kullandıkları çalışmalarında ve son olarak Hetsroni ve ark. ${ }^{[8]}$, meniskokapsüler ayrılması olan olgularının cerrahilerinde hepsi içeride dikiş tekniği kullandıkları çalışmalarında, erken dönemde hareket ama kısıtlı ağırlık aktarma protokolleriyle, sırasıyla $\% 78, \% 68, \% 68$ ve \%83 başarı elde ettiklerini bildirmişlerdir. Rehabilitasyon süreçleri Tablo 3'te gösterilmiştir. Choi ve ark. ${ }^{[5]}, 36,3$ aylık ortalama takip sonucunda, Tegner skorunun rehabilitasyon ile yaralanma öncesine oranla 4'ten 5,7'e ve Lysholm skorunun da 75'e geldiğini, Englund ve ark. ${ }^{[6]}, 52$ aylık ortalama takip sonucunda, Tegner skorunun rehabilitasyon ile yaralanma öncesi altı puanı koruduğunu ve Lysholm skorunun da 94,7'e geldiğini, Krych ve ark. ${ }^{[7]}, 5$, 8 yıllık ortalama takip sonucunda, Tegner skorunun 8'e ve International Knee Documentation Committee (IKDC) diz skorunun 65,1 'den 89,4'e geldiğini, Hetsroni ve ark. ${ }^{8]}$ ise 31 aylık ortalama takip sonucunda, Tegner skorunun 4'ten 7'ye ve IKDC skorunun da 87'e geldiğini belirtmişlerdir.

\section{Hareket ve Ağırlık Aktarma Kısıtlanmış Rehabilitasyon Protokolü}

Lind ve ark. ${ }^{[1]}$, vertikal yırtığa yönelik hepsi içeride dikiş tekniği kullandıkları çalışmalarında, Majewski ve ark. ${ }^{[9]}$, vertikal yırtığa yönelik dışarıdan içeriye dikiş tekniği kullandıkları çalışmalarında, Ahn ve ark. ${ }^{[10]}$, horizontal yırtığa yönelik hepsi içeride dikiş tekniği kullandıkları çalışmalarında, Soejima ve ark. ${ }^{[11]}$, Horibe ve ark. ${ }^{[12]}$ ve Suganuma ve ark.. ${ }^{[2]}$, vertikal yırtık tamiri için içeriden dışarıya dikiş tekniği kullandıkları çalışmalarında, Haklar ve ark. ${ }^{[13]}$, radyal yırtık tamiri için içeriden dışarıya dikiş tekniği kullandıkları çalışmalarında, Ahn ve ark.[14], kova sapı yırtığının tamiri için hepsi içeride dikiş tekniği kullandıkları çalışmalarında, Raza ve ark. ${ }^{[15]}$, kova sapı yırtığının tamiri için içeriden dışarıya dikiş tekniği kullandıkları çalışmalarında, klinik olarak sırasıyla $\% 64, \% 76, \% 76, \% 86, \% 25$, $\% 100, \% 91$ ve \%80 başarılı sonuçlar elde etmişlerdir. Rehabilitasyon süreçleri Tablo 4'te gösterilmiştir. Lind ve ark. ${ }^{[1]}$, minimum iki yıllık takip sonucunda, Tegner skorunun rehabilitasyon ile yaralanma öncesine oranla $5,1 \pm 2,4$ 'ten 4,1 $\pm 2,1$ 'e geldiğini, Majewski ve ark. ${ }^{[9]}, 10$ yıllık ortalama takip sonucunda, yaralanma öncesi 7 puan olan Tegner skorunun rehabilitasyon ile 6 puana ve Lysholm skorunun da 94'e geldiğini, Ahn ve ark. ${ }^{[10]}$, 45,6 yıllık ortalama takip sonucunda, Tegner skorunun 6,8 'e ve Lysholm skorunun da 48'den 92'e geldiğini, Suganuma ve ark. ${ }^{[2]}, 2,6$ yıllık ortalama takip sonucunda, Tegner skorunun 5,5'ten 4,2'ye ve Lysholm skorunun da 86,5'e geldiğini, Haklar ve ark.[13], 31 aylık ortalama takip sonucunda, Lysholm skorunun 94,2'ye geldiğini, Ahn ve ark. ${ }^{[14]}, 59$ aylık ortalama takip sonucunda, Tegner skorunun 3'ten 7'ye ve Lysholm skorunun da 94,6'ya geldiğini, Raza ve ark.[15], 17 aylık ortalama takip sonucunda, Lysholm skorunun 86,5 'e ve Tegner skorunun da 5,5'ten 4,2'ye geldiğini belirtmişlerdir. Soejima ve ark. ${ }^{[11]}$ ve Horibe ve ark. ${ }^{[12]}$, çalışmalarında herhangi bir subjektif değerlendirme skoru vermedikleri için, burada paylaşılamamıştır.

\section{Menisküs Kök Tamiri Sonrası Rehabilitasyon Protokolleri}

Kök tamiri sonrası rehabilitasyon ile ilgili literatürde çok az yayın bulunmaktadır. ${ }^{[16]}$ Koruma fazı, ağırık

Tablo 3. Ağırlık aktarma kısıtlanmış rehabilitasyon protokolü

\begin{tabular}{|c|c|c|c|c|c|}
\hline Çalışma & $\mathrm{NEH}$ & Ağırlık aktarma & Koşma & Spora dönüş & Rehabilitasyon detayı \\
\hline Choi ve ark. ${ }^{[5]}$ & $0-6$ hafta: $0-90^{\circ}$ & 0-6 hafta: PUBAA & 12. hafta & 24. hafta & $\begin{array}{l}\text { 0-4 hafta: Kademeli } \\
\text { ilerleyen ağırlık aktarma } \\
\text { 12. hafta: Tam çömelme }\end{array}$ \\
\hline Englund ve ark..$^{[6]}$ & $\begin{array}{l}0-6 \text { hafta: } 0-90^{\circ} \\
>6 \text {. hafta: Tam NEH }\end{array}$ & $\begin{array}{l}0-3 \text { hafta: KAA } \\
0-6 \text { hafta: } 90^{\circ} \text { 'den } \\
\text { fazla fleksiyon } \\
\text { pozisyonunda HAA }\end{array}$ & $x$ & 12. hafta & $\begin{array}{l}0-3 \text { hafta: } A K Z \\
\text { egzersizlerinden kaçınılmalı. }\end{array}$ \\
\hline Krych ve ark..$^{[7]}$ & $0-6$ hafta: $0-90^{\circ}$ & $0-4$ hafta: KAA & $x$ & 16-24. hafta & $\begin{array}{l}\text { 0-16 hafta: Çömelme } \\
\text { ve ekstremite üzerinde } \\
\text { dönmekten kaçınılmalı. }\end{array}$ \\
\hline Hetsroni ve ark. ${ }^{[8]}$ & $\begin{array}{l}0-6 \text { hafta: } 0-90^{\circ} \\
>6 \text {. hafta: Tam NEH }\end{array}$ & $\begin{array}{l}0-3 \text { hafta: HAA } \\
>4 \text {. hafta: TAA }\end{array}$ & 16. hafta & 24. hafta & $\begin{array}{l}\text { 0-24 hafta: Çömelmeden } \\
\text { kaçınılmalı }\end{array}$ \\
\hline
\end{tabular}

NEH, normal eklem hareketi; PUBAA, parmak ucuna basarak ağılık aktarma; HAA, hiç ağırlık aktarmama; KAA, kısmi ağılık aktarma; TAA, tam ağılık aktarma; AKZE, açık kinetik zincir egzersizleri; $X$, uygulanmamış/belirtilmemiş. 
Tablo 4. Hareket ve ağırık aktarma kısıtlanmış rehabilitasyon protokolü

\begin{tabular}{|c|c|c|c|c|c|}
\hline Çalışma & $\mathrm{NEH}$ & Ağırlık aktarma & Koşma & Spora dönüş & Rehabilitasyon detayı \\
\hline Lind ve ark. ${ }^{[1]}$ & $\begin{array}{l}0-2 \text { hafta: } 0-30^{\circ} \\
\text { 3-4 hafta: } 0-60^{\circ} \\
5-6 \text { hafta: } 0-90^{\circ}\end{array}$ & $\begin{array}{l}\text { 0-2 hafta: HAA } \\
\text { 3-4 hafta: PUBAA } \\
\text { 5-6 hafta: TEKAA }\end{array}$ & 12. hafta & 24. hafta & 0-2 hafta: Dizlik \\
\hline Suganuma ve ark. ${ }^{[2]}$ & 0-3 hafta: Hareketsiz & $\begin{array}{l}0-4 \text { hafta: KAA } \\
\text { 8. hafta: TAA }\end{array}$ & $x$ & 20. hafta & $\begin{array}{l}0-3 \text { hafta: Alçı kullanılmalı } \\
\text { 12. hafta: Topuk üzerine } \\
\text { oturma }\end{array}$ \\
\hline Majewski ve ark. ${ }^{[9]}$ & $0-6$ hafta: $0-60^{\circ}$ & $\begin{array}{l}\text { 0-6 hafta: Tam } \\
\text { ekstansiyonda KAA ve } \\
\text { fleksiyonda HAA }\end{array}$ & $x$ & 16. hafta & SPH ilk gün başlanmalı. \\
\hline Ahn ve ark. ${ }^{[10]}$ & $\begin{array}{l}0-2 \text { hafta: } 0-60^{\circ} \\
\text { 4. hafta: } 0-90^{\circ} \\
\text { 6. hafta: } 0-120^{\circ} \\
\text { 8. hafta: Tam NEH }\end{array}$ & 0-4 hafta: KAA & $x$ & $x$ & $\begin{array}{l}\text { 0-6 hafta: Ekstansiyon } \\
\text { dizliği } \\
0-4 \text { hafta: KD ile yürüme }\end{array}$ \\
\hline Soejima ve ark. ${ }^{[11]}$ & 0-2 hafta: Hareketsiz & 5. hafta: TAA başla & $x$ & 16-24. hafta & - \\
\hline Horibe ve ark. ${ }^{[12]}$ & 0-2 hafta: Hareketsiz & 5. hafta: TAA başla & $x$ & 16-24. hafta & - \\
\hline Haklar ve ark. ${ }^{[13]}$ & 0-6 hafta: Hareketsiz & 6-8 hafta: HAA & $x$ & 16. hafta & $\begin{array}{l}\text { 16. hafta: } 120^{\circ} \text { 'yi geçen } \\
\text { çömelme }\end{array}$ \\
\hline Ahn ve ark. ${ }^{[14]}$ & 0-2 hafta: Hareketsiz & 2. gün: KAA başla & $x$ & $x$ & $\begin{array}{l}\text { 0-2 hafta: Dizi tam } \\
\text { ekstansiyonda tutan dizlik } \\
\text { kullanılmalı, sonrasında } \\
\text { menteşeli dizliğe geçilmeli. }\end{array}$ \\
\hline Raza ve ark. ${ }^{[15]}$ & 0-4 hafta: Hareketsiz & 4-6 hafta: KAA başla & 12. hafta & 24. hafta & $\begin{array}{l}0-4 \text { hafta: Dizlik } \\
\text { kullanılmalı. }\end{array}$ \\
\hline
\end{tabular}

NEH, normal eklem hareketi; PUBAA, parmak ucuna basarak ağılık aktarma; HAA, hiç ağılık aktarmama; KAA, kısmi ağılık aktarma; TEKAA, tolere edebildiği kadar ağılık aktarma; TAA, tam ağılık aktarma; SPH, sürekli pasif hareket (CPM); KD, koltuk değneği; $X$, uygulanmamış/belirtilmemiş.

aktarma toleransına göre rehabilitasyon fazı, dayanıklılık fazı, kuwvetlendirme fazı ve spora dönüş fazından oluşan örnek program, Tablo 5'te gösterilmiştir. Mediyal arka köke $0^{\circ}$ ile $30^{\circ}$ diz fleksiyonu arasında çok yük binmediği halde, $30^{\circ}$ fleksiyonda lateral arka köke çok yük biner. Diz fleksiyonunda $30^{\circ}$ 'den $60^{\circ}$ 'ye ilerlenirken, hem mediyal hem de lateral arka köke çok yük biner; $90^{\circ}$ ve sonrası ise kökler üzerindeki yük miktarı dört kat artar. ${ }^{[17]}$ Kök tamir rehabilitasyonunda izole hamstring aktivitesi ve hangi açılarda menisküslerin hangi köküne fazla yük bindiği bilinmelidir.

\section{MENISKÜS TAMIRLERI SONRASI SPORA DÖNÜŞ}

Menisküs tamiri, ardından uzamış bir rehabilitasyon sürecine ihtiyaç duyan, kompleks bir tedavi seçeneğidir. ${ }^{[18]}$ Aynı zamanda, menisküs tamirleri daha iyi klinik sonuçlara ve parsiyel menisektomi ile kıyaslandığında daha az kıkırdak hasar riskine sahip olması nedeniyle giderek daha çok tercih edilmektedir. ${ }^{[19,20]}$
Bu avantajları nedeniyle de, başta elit sporcular olmak üzere, spor yapan aktif hastalarda ilk sıraları alan bir cerrahi teknik haline gelmiştir. ${ }^{[21]}$

İzole menisküs tamirlerinin sonucunda spora dönüş oranı; profesyonel sporcularda $\% 86$, profesyonel olmadığı halde düzenli spor yapan aktif bireylerde ise \%90'dır. İşlevsel sonuç skorları da iyi veya mükemmel olarak kaydedilmiştir. Yaralanma öncesi ve cerrahiyi takiben başlatılan rehabilitasyon sonucunda elde edilen Tegner skorları da birbirine yakın bulunmuştur $(6,3 \pm 1,1$ ve $5,7 \pm 0,8)$. $^{[22]}$

Periferal menisküs tamiri yapılan ve hem kuadriseps hem de hamstring izometrik kassal kuvvet kaybı \%30'dan daha az olan bireyler, 20. haftadan itibaren koşu programına başlayabilir. Kompleks menisküs tamiri olan kişilerde bu süre 30 haftaya kadar uzatılabilir. Hasta, koşu programına yürü-koş kombinasyonu ve 18-91 metre aralığında başlamalıdır. ilk olarak, hasta kendi normal hızının \%25 ila \%50'sinde 
Tablo 5. Kök tamiri sonrası rehabilitasyon protokolü[16]

\begin{tabular}{|c|c|c|c|}
\hline Faz & Dikkat edilecekler / Yasaklar & Amaçlar / ilerleme ölçütleri & Uygulamalar \\
\hline $\begin{array}{l}\text { Koruma Fazı } \\
(0-6 \text { hafta })\end{array}$ & $\begin{array}{l}\text { a. HAA } \\
\text { b. } 0-2 \text { hafta: PNEH } 0-90^{\circ} \\
\text { c. NEH sınırı tolerasyona göre } \\
\text { ilerlenecek } \\
\text { d. İzole Hamstring aktivitesi } \\
\text { yasak! }\end{array}$ & $\begin{array}{l}\text { a. Cerrahiyi koru } \\
\text { b. Eklem efüzyonunu azalt } \\
\text { c. Tam NEH kazandır }\end{array}$ & $\begin{array}{l}\text { a. NEH egzersizleri } \\
\text { b. Patella, patellar tendon\&kuadriseps } \\
\text { mobilizasyonu } \\
\text { c. Terminal ekstansiyonda kuadriseps aktivasyonuna } \\
\text { odaklan } \\
\text { d. Thomas germe pozisyonunda ve güvenli NEH } \\
\text { sınırında kuadriseps germe egzersizleri } \\
\text { e. Gastroknemius germe } \\
\text { f. Kalça ve core kuvvetlendirme } \\
\text { g. Üst ekstremite ve core kuvvetlendirme }\end{array}$ \\
\hline $\begin{array}{l}\text { Ağırlık Aktarma } \\
\text { Toleransına Göre } \\
\text { Rehabilitasyon Fazı } \\
\text { (7-9 hafta) }\end{array}$ & $\begin{array}{l}\text { a. Ağırlık aktarma miktarını } \\
\text { kademeli ilerlet } \\
\text { b. KKZ aktivitelerinde diz } \\
\text { fleksiyonu } 40^{\circ} \text { 'yi geçmesin } \\
\text { c. KKZ aktivitelerini ağılık } \\
\text { aktarma sınırlarında yaptır }\end{array}$ & $\begin{array}{l}\text { a. TAA kazan } \\
\text { b. Yürüme paternini düzelt } \\
\text { c. Eklem effüzyonu yok } \\
\text { d. Ayakta durma ve yürüme } \\
\text { tolerasyonu en az } 25 \mathrm{dk} \text { olmalı }\end{array}$ & $\begin{array}{l}\text { a. Ağırlık aktarma sınırlarında denge egzersizleri } \\
\text { b. Parmak ucunda yükselme } \\
\text { c. "Leg-press" } \\
\text { d. Tam NEH kazanıldığında iki bacak üzerinde } \\
\text { çömelme } \\
\text { e. Dirençsiz sabit bisiklet }\end{array}$ \\
\hline $\begin{array}{l}\text { Endürans Fazı } \\
(10-15 \text { hafta })\end{array}$ & $\begin{array}{l}\text { KKZ aktiviteleri sırasında diz } \\
\text { fleksiyonu } 70^{\circ} \text { 'yi geçmesin }\end{array}$ & $\begin{array}{l}45^{\circ} \text { 'diz fleksiyonunda tek } \\
\text { bacak çömelme hareketini } 90 \\
\text { sn yapmalı }\end{array}$ & $\begin{array}{l}\text { a. İki bacak üzerinde çömelme } \\
\text { b. Statik hamle } \\
\text { c. Dinamik hamle } \\
\text { d. Dirençli sabit bisiklet } \\
\text { *Egzersiz ölçütleri: } 3 \text { set / 15-25 tekrar / 30-60 sn } \\
\text { dinlenme ve 3-4 gün/hafta }\end{array}$ \\
\hline $\begin{array}{l}\text { Kuwetlendirme Fazı } \\
\text { (16-21 hafta) }\end{array}$ & $\begin{array}{l}\text { 20. haftaya kadar KKZ } \\
\text { aktivitelerinde diz fleksiyonu } \\
90^{\circ} \text { 'yi geçmesin }\end{array}$ & $\begin{array}{l}\text { a. Kuadriseps indeksi \%80'den } \\
\text { fazla olmalı } \\
\text { b. Diğer taraf ile } \\
\text { kıyaslandığında } Y \text { denge } \\
\text { testinde öne uzanma }<8 \mathrm{~cm}\end{array}$ & $\begin{array}{l}\text { a. Tek bacak üzerinde çömelme } \\
\text { b. Tek bacak "dead-lift" } \\
\text { c. Basamak inme-çıkma } \\
\text { d. Çok yönlü hamle } \\
\text { e. Dirençli sabit bisiklet } \\
\text { *Egzersiz ölçütleri: } 3 \text { set / 8-12 tekrar / 2-3 dk } \\
\text { dinlenme ve } 3 \text { gün/hafta }\end{array}$ \\
\hline $\begin{array}{l}\text { Spora Dönüş Fazı } \\
(+22 . \text { hafta })\end{array}$ & $\begin{array}{l}6 \text { aydan önce derin çömelme } \\
\text { yasak }\end{array}$ & $\begin{array}{l}\text { a. Vail Sport Testinden başarılı } \\
\text { olmak }(>46 / 54) \\
\text { b. Diğer tarafile } \\
\text { kıyaslandığında } Y \text { denge } \\
\text { testinde öne uzanma }<5 \mathrm{~cm} \\
\text { olmalı } \\
\text { c. Y denge testinde bileşik skor } \\
>\% 94 \text { olmalı } \\
\text { d. Kuadriseps indeksi >\%90 } \\
\text { e. Diğer taraf ile } \\
\text { kıyaslandığında Modifiye } \\
\text { Agility T-testinde }>\% 90 \text { olmalı } \\
\text { f. Tek bacak öne hoplama } \\
\text { testinde }>\% 90 \text { olmalı }\end{array}$ & $\begin{array}{l}\text { a. Çift ve tek bacak sıçrama eğitimi } \\
\text { b. Yana hoplama (dirençsiz) } \\
\text { c. Ani dönme aktiviteleri } \\
\text { d." Ladder drill” egzersizleri } \\
\text { *Koşu programı ilerlemesi: } \\
\text { - Başlangıç: } 15-20 \mathrm{dk} \text { boyunca: } 4 \mathrm{dk} \text { yürüme + } 1 \mathrm{dk} \\
\text { koşu } \\
-1 \text { hafta sonra: } 20 \mathrm{dk} \text { boyunca: } 3 \mathrm{dk} \text { yürüme+2 dk } \\
\text { koşu } \\
\text { - } 2 \text { hafta sonra: } 20 \mathrm{dk} \text { boyunca: } 2 \mathrm{dk} \text { yürüme+3 dk } \\
\text { koşu } \\
-3 \text { hafta sonra: } 20 \text { dakika boyunca: } 1 \mathrm{dk} \text { yürüme + } \\
4 \mathrm{dk} \text { koşu }\end{array}$ \\
\hline
\end{tabular}

NEH, normal eklem hareketi; PNEH, pasif normal eklem hareketi; HAA, hiç ağılık aktarmama; TAA, tam ağılık aktarma; KKZ, kapalı kinetik zincir.

koşma programına alınmalıdır. Düz koşuda normal hıza ulaştıktan sonra, yanlara, geriye ve çapraz koşulara başlamalıdır. Hız ve çevikliği geliştirmek için 18 metre gibi kısa mesafeler kullanılmalıdır. Sekiz çizme, yatay-çapraz (carioca) koşu, yan yan koşu ise çeviklik ve propriyosepsiyonu geliştirmek için önemlidir. İlerleyici pliometrik egzersizlere ise, koşu programı başarıyla tamamlandıktan sonra yaklaşık altıncı aydan itibaren başlanabilir. Büyük periferal yırtık ve kompleks tamiri yapılan bireyler için ilerleyici pliometrik egzersizlere dokuzuncu aydan önce geçilmemelidir. ${ }^{[23]}$ Spora dönüş sürecinin bir hayli uzun olmasının etkisini azaltmak için, rehabilitasyon programına aerobik egzersizler spora dönüş fazından çok daha önce mutlaka eklenmelidir. Menisküs tamirini takiben aerobik egzersiz protokolü Tablo 6'da gösterilmiştir. 
Tablo 6. Menisküs tamirini takiben aerobik egzersiz protokolü[23]

\begin{tabular}{|c|c|c|c|c|c|}
\hline Cerrahi sonrası süre $\&$ frekans & Kol ergometresi & Sabit bisiklet & Suda yürüme & Yüzme & Yürüme \\
\hline $3-4$ hafta \& 1-2 kez/gün & $10 \mathrm{dk}$ & & & & \\
\hline 5-6 hafta \& 2 kez/gün & $10 \mathrm{dk}$ & & & & \\
\hline $7-8$ hafta $\& 1-2$ kez/gün & $15 \mathrm{dk}$ & $15 \mathrm{dk}$ & & & \\
\hline $\begin{array}{l}\text { 9-12 hafta \& } 1 \text { kez/gün } \\
\text { (tek bir aktivite) }\end{array}$ & & $15 \mathrm{dk}$ & $15 \mathrm{dk}$ & $15 \mathrm{dk}$ & $15 \mathrm{dk}$ \\
\hline $\begin{array}{l}\text { 13-26 hafta \& } 3 \mathrm{kez} / \text { hafta } \\
\text { (tek bir aktivite) }\end{array}$ & & $20 \mathrm{dk}$ & $20 \mathrm{dk}$ & $20 \mathrm{dk}$ & $20 \mathrm{dk}$ \\
\hline 20 hafta $\& 3 \mathrm{kez} / \mathrm{hafta}$ & & $20-30 \mathrm{dk}$ & $20-30 \mathrm{dk}$ & $20-30 \mathrm{dk}$ & $20-30 \mathrm{dk}$ \\
\hline $27+$ hafta $\& 3 \mathrm{kez} /$ hafta & & $20-30 \mathrm{dk}$ & $20-30 \mathrm{dk}$ & $20-30 \mathrm{dk}$ & $20-30 \mathrm{dk}$ \\
\hline
\end{tabular}

\section{SONUÇ}

Menisküs yırtıklarının görülme oranı sorgulandığında, cinsiyetler arasında farklı oranlar dikkati çekmektedir. Erkeklerde 9/10.000 kadınlarda 4,2/10.000 olarak belirtilmekte ve bu yırtıklar en fazla üçüncü ve beşinci dekadlar arasında bulgu vermektedir. ${ }^{[24]}$

Menisküsler, günlük yaşam ve spor aktivitelerinin istenen kalitede ve tatmin edici şekilde sürdürülebilmesi için kritik öneme sahip anatomik yapılardır. Gerek histolojik, gerek morfolojik yapılarının sağladığı özelliklerle, fonksiyonel bir eklemin önemli ihtiyaçlarını karşılar. Bu fonksiyonları; dengelenmiş yük aktarımı, yük emilimi, eklem stabilitesi, lubrikasyon, eklem kartilajının beslenmesi, eklem yüzleri arası uyumun sağlanması şeklinde sıralayabiliriz. Menisküslerin bahsedilen bu fonksiyonlarının kaybı, eklem içi temas basınçlarında artışa sebep olarak, zaman içinde kıkırdak hasarlanmaları ile sonuçlanır. ${ }^{[25-27]}$ Menisektomi yapılmış dizlerde bu yaralanma miktarının ana belirleyicisinin, çıkarılan menisküs miktarı olduğu belirtilmiştir. ${ }^{[28]}$ Menisküs hacmindeki \%16-34'lük kayıp, temas basıncında \%350'lik bir artışla sonuçlanır. ${ }^{[29]}$ $\mathrm{Bu}$ nedenlerden dolayı, yaralanmış bir menisküsün tedavisinde, çeşitli oranlarda ve yerleşimlerde yapılan menisektomiler yerine, onarım tekniklerinin kullanılması gerektiğini söyleyebiliriz.

Menisküs onarımı sonrası eklem fonksiyonlarının istenen düzeye ulaşmasında, rehabilitasyon programları önemli yer tutar. Güncel uygulamalarda, standart yaklaşımlardan hızlandırılmış protokollere, çeşitli kliniklerde farklı uygulamalar tercih edilmektedir. Tamamen eklem içi menisküs onarımı yapılmış olgularda, hızlandırılmış rehabilitasyon protokolü ile standart rehabilitasyon protokollerini karşılaştıran derleme çalışmalarında, benzer klinik sonuçlar ve tekrarlayan yırtık oranları bildirilmiştir. ${ }^{[30,31]}$ Ayrıca, menisküs onarımı sonrası sınırlandırılmış yük verme protokolü ile \%70-94, erken yük verme ve eklem hareket açıklığı egzersizleri ile \%64-96 gibi iyi sonuçlar ile, birbirine yakın ve tatmin edici oranlar bildirilmiştir. [32] İzole menisküs onarımı sonrası standart ve hızlandırılmış protokoller karşılaştırıldığında, benzer klinik sonuçlar bildirilmiştir. Hızlandırılmış protokollerin tekrar yırtık oluşumu ve yetersiz klinik sonuç oranlarını arttırmadığı bildirilmiştir. ${ }^{[33]}$ Özetle, hızlandırılmış rehabilitasyon programları ile ilgili yapılmış çalışmalarda bir artış görülmekte ve tatmin edici sonuçlar bildirilmektedir. Ancak, hala menisküs yırtık tipi ve yerleşimi, büyüklüğü ve bireye ait kişisel özellikler (gerek anatomik, gerek aktivite açısından) ele alınarak oluşturulmuş, daha homojen gruplar üzerinde yapılmış yeterince çalışma bulunmamaktadır. Gelecekte, kişiye ve menisküs lezyonuna özel ayrıştırılmış rehabilitasyon protokolleri ile daha başarılı klinik sonuçlar elde etmemiz mümkün olabilir.

\section{KAYNAKLAR}

1. Lind M, Nielsen T, Fauno P, Lund B, Christiansen SE. Free rehabilitation is safe after isolated meniscus repair: a prospective randomized trial comparing free with restricted rehabilitation regimens. Am J Sports Med 2013;41(12):27538. Crossref

2. Suganuma J, Mochizuki R, Yamaguchi K, Inoue $Y$, Yamabe $E$, Ueda $Y$, Fujinaka T. Cam impingement of the posterior femoral condyle in medial meniscal tears. Arthroscopy 2010;26(2):173-83. Crossref

3. Stein T, Mehling AP, Welsch F, von Eisenhart-Rothe R, Jager A. Long-term outcome after arthroscopic meniscal repair versus arthroscopic partial meniscectomy for traumatic meniscal tears. Am J Sports Med 2010;38(8):1542-8. Crossref

4. Eggli S, Wegmuller H, Kosina J, Huckell C, Jakob RP. Longterm results of arthroscopic meniscal repair: an analysis of isolated tears. Am J Sports Med 1995;23(6):715-20. Crossref 
5. Choi NH, Kim TH, Son KM, Victoroff BN. Meniscal repair for radial tears of the midbody of the lateral meniscus. Am J Sports Med 2010;38(12):2472-6. Crossref

6. Englund M, Roos EM, Roos HP, Lohmander LS. Patientrelevant outcomes fourteen years after meniscectomy: influence of type of meniscal tear and size of resection. Rheumatology (Oxford) 2001;40(6):631-9. Crossref

7. Krych AJ, Mclntosh AL, Voll AE, Stuart MJ, Dahm DL. Arthroscopic repair of isolated meniscal tears in patients 18 years and younger. Am J Sports Med 2008;36(7):1283-9. Crossref

8. Hetsroni I, Lillemoe K, Marx RG. Small medial meniscocapsular separations: a potential cause of chronic medial-side knee pain. Arthroscopy 2011;27(11):1536-42. Crossref

9. Majewski M, Stoll R, Widmer H, Müller W, Friederich NF. Mid term and long-term results after arthroscopic suture repair of isolated, longitudinal, vertical meniscal tears in stable knees. Am J Sports Med 2006;34(7):1072-6. Crossref

10. Ahn JH, Kwon OJ, Nam TS. Arthroscopic repair of horizontal meniscal cleavage tears with marrow-stimulating technique. Arthroscopy 2015;31(1):92-8. Crossref

11. Soejima $T$, Murakami $H$, Inoue $T$, Kanazawa $T$, Katouda $M$, Nagata K. Cartilage change after arthroscopic repair for an isolated meniscal tear. Kurume Med J 2005;52(4):127-31. Crossref

12. Horibe S, Shino K, Maeda A, Nakamura N, Matsumoto $\mathrm{N}$, Ochi T. Results of isolated meniscal repair evaluated by second-look arthroscopy. Arthroscopy 1996;12(2):150-5. Crossref

13. Haklar U, Kocaoglu B, Nalbantoglu U, Tuzuner T, Guven O. Arthroscopic repair of radial lateral meniscus tear by double horizontal sutures with inside-outside technique. Knee 2008;15(5):355-9. Crossref

14. Ahn JH, Kim KI, Wang JH, Kyung BS, Seo MC, Lee $\mathrm{SH}$. Arthroscopic repair of bucket-handle tears of the lateral meniscus. Knee Surg Sports Traumatol Arthrosc 2015;23(1):205-10. Crossref

15. Raza H, Abbas K, Umer M. Arthroscopic repair of meniscal tears with inside-out technique. J Pak Med Assoc 2011;61(1):10-4

16. Mueller BT, Moulton SG, O’Brien L, LaPrade RF. Rehabilitation Following Meniscal Root Repair: A Clinical Commentary. J Orthop Sports Phys Ther 2016;46(2):104-13. Crossref

17. Becker R, Wirz D, Wolf C, Göpfert B, Nebelung W, Friederich $\mathrm{N}$. Measurement of meniscofemoral contact pressure after repair of bucket-handle tears with biodegradable implants. Arch Orthop Trauma Surg 2005;125(4):254-60. Crossref

18. Stärke C, Kopf S, Petersen W, Becker R. Meniscal repair. Arthroscopy 2009;25(9):1033-44. Crossref

19. Xu C, Zhao J. A meta-analysis comparing meniscal repair with meniscectomy in the treatment of meniscal tears: the more meniscus, the better outcome? Knee Surg Sports Traumatol Arthrosc 2015;23(1):164-70. Crossref
20. Paxton ES, Stock MV, Brophy RH. Meniscal repair versus partial meniscectomy: a systematic review comparing reoperation rates and clinical outcomes. Arthroscopy 2011;27(9):1275-88. Crossref

21. Alvarez-Diaz P, Alentorn-Geli E, Llobet F, Granados N, Steinbacher G, Cugat R. Return to play after all-inside meniscal repair in competitive football players: a minimum 5-year follow-up. Knee Surg Sports Traumatol Arthrosc 2016;24(6):1997-2001. Crossref

22. Eberbach $\mathrm{H}$, Zwingmann J, Hohloch L, Bode G, Maier D, Niemeyer P, Südkamp NP, Feucht MJ. Sport-specific outcomes after isolated meniscal repair: a systematic review. Knee Surg Sports Traumatol Arthrosc 2018;26(3):762-71. Crossref

23. Noyes FR, Heckmann TP, Barber-Westin SD. Meniscus repair and transplantation: a comprehensive update. J Orthop Sports Phys Ther 2012;42(3):274-90. Crossref

24. Hede A, Jensen DB, Blyme P, Sonne-Holm S. Epidemiology of meniscal lesions in the knee: 1,215 open operations in Copenhagen 1982-84. Acta Orthop Scand 1990;61(5):4357. Crossref

25. Krause WR, Pope MH, Johnson RJ, Wilder DG. Mechanical changes in the knee after meniscectomy. J Bone Joint Surg Am 1976;58(5):599-604. Crossref

26. Allen PR, Denham RA, Swan AV. Late degenerative changes after meniscectomy. Factors affecting the knee after operation. J Bone Joint Surg Br 1984;66-B(5):666-71. Crossref

27. Jorgensen $U$, Sonne-Holm S, Lauridsen F, Rosenklint A. Longterm Follow-up of Meniscectomy in Athletes. A Prospective Longitudinal Study. J Bone Joint Surg Br 1987;69-B(1):80-3. Crossref

28. CoxJS, Nye CE, Schaefer WW, Woodstein IJ. The degenerative effects of partial and total resection of the medial meniscus in dogs' knees. Clin Orthop Relat Res 1975;109:178-83. Crossref

29. Seedhom BB, Hargreaves DJ. Transmission of load in the knee joint with special reference to the role of the menisci, part II. Experimental results, discussions, and conclusions. Eng Med Biol 1979;8(4):220-8. Crossref

30. Vascellari A, Rebuzzi E, Schiavetti S, Coletti N. All-inside meniscal repair using the FasT-Fix. meniscal repair system: is still needed to avoid weight bearing? A systematic review. Musculoskelet Surg 2012;96(3):149-54. Crossref

31. O'Donnell K, Freedman KB, Tjoumakaris FP. Rehabilitation Protocols After Isolated Meniscal Repair: A Systematic Review. Am J Sports Med 2017;45(7):1687-97. Crossref

32. VanderHave KL, Perkins C, Le M. Weightbearing Versus Nonweightbearing After Meniscus Repair. Sports Health 2015;7(5):399-402. Crossref

33. Perkins B, Gronbeck KR, Yue RA, Tompkins MA. Similar failure rate in immediate post-operative weight bearing versus protected weight bearing following meniscal repair on peripheral, vertical meniscal tears. Knee Surg Sports Traumatol Arthrosc 2017. Crossref 